\title{
VALUE OF SPECT IN INTRACTABLE EPILEPSY
}

The role of SPECT in 65 children undergoing video-EEG telemetry for intractable seizures was evaluated at Sydney Children's Hospital, New South Wales, Australia. Patients with a well-localized epilepsy syndrome and lesion on MRI had the highest concordance with SPECT ( $86 \%$ in the temporal group and $58 \%$ in the extratemporal group). In those not localized by MRI, SPECT provided localizing data in more than 50\%. Ictal SPECT was of no greater prognostic value before surgery in 23 patients studied with a localized MRI lesion, but it provided additional localization of practical value in patients without lesions. Localization of SPECT to the surgical site was not predictive of surgical outcome. SISCOM confirmed conventional SPECT analysis in 19 of 25 cases, and localized lesions in 4 children in whom SPECT had failed. (Lawson JA, O'Brien TJ, Bleasel AF et al. Evaluation of SPECT in the assessment and treatment of intractable childhood epilepsy. Neurology November (1 of 2) 2000;55:1391-1393). (Reprints: Dr AME Bye, Department of Paediatric Neurology, Sydney Children's Hospital, Randwick, 2031, New South Wales, Australia).

COMMENT. SPECT may be of value in presurgical localization of lesions in children with a normal MRI or nonlocalized epilepsy syndrome.

SPECT and infantile spasms. Focal temporal lobe hypoperfusion is demonstrated on SPECT in infants with spasms, despite normal MRI (Miyazaki M et al. 1994). This series and others using PET are reviewed fully in Progress in Pediatric Neurology III, 1997;pp39-41.

\section{ANTIEPILEPTIC DRUG WITHDRAWAL IN PARTIAL EPILEPSY}

The optimal time of discontinuing anticonvulsant treatment in children with cryptogenic partial epilepsy was evaluated at the Universities of Chieti and Siena, Italy. In two groups of 45 and 44 children whose therapy was discontinued slowly (over a 6 month period) after 1 and 2 years from the last seizure, recurrence rates after 5 years follow-up were $29 \%$ and $25 \%$, respectively. A 1 year seizure-free period is a safe interval for discontinuation of therapy in children with cryptogenic partial seizures. (Verrotti A, Morresi S, Basciani F et al. Discontinuation of anticonvulsant therapy in children with partial epilepsy. Neurology Nov (1 of 2) 2000;55:1393-1395). (Reprints: Dr Alberto Verrotti, Department of Medicine, Section of Pediatrics, University of Chieti, Opsdale Policlinico, Via dei Vestini 5, 66013 Chieti, Italy).

COMMENT. Therapy may be discontinued gradually after a 1 year seizurefree period in children treated for cryptogenic partial seizures. A relapse rate of approximately $25 \%$ is not significantly lower if treatment is continued for 2 years.

\section{TERATOGENIC POTENTIAL OF ANTIEPILEPTIC DRUGS}

The effect of antiepileptic drugs on intrauterine growth is reviewed from the Center for Human Molecular Genetics, Nebraska, and the University of Newcastle upon Tyne, UK. The differentiation of drug effects from those of the genotype of the exposed infant is important in the phenotypic expression of any dysmorphism. In a large Swedish study of 963 infants, with data collected prospectively over 3 periods, from 1973 to 1997, carbamazepine had the greatest negative effect on fetal body growth, although the degree was minor.

In a cohort of 400 women with epilepsy studied prospectively in Northern England, fetal malformations in $5 \%$ were significantly more common than among 
the local population. Less than $50 \%$ planned their pregnancy, because of failed oral contraceptive, $71 \%$ were still having seizures, and 157 of 252 questioned admitted incomplete drug compliance. A follow-up of 105 infants in the Northern English cohort identified 23 developmentally delayed infants, 7 severe.

In Nebraska, a susceptibility gene for valproate-induced anomalies in the mouse has been identified, syntenic with the short arm of human chromosome 16 . (Finnell RH, Burn J. Effect of anti-epileptic drugs on intrauterine growth. Lancet November 4, 2000;356:1537). (Respond: Dr Richard H Finnell, Center for Human Molecular Genetics, University of Nebraska Medical Center, Omaha, Nebraska 68198, USA; Dr John Burn, Northern Region Genetics Service, University of Newcastle upon Tyne, Newcastle upon Tyne, UK).

COMMENT. This review is important because the teratogenic potential of newly approved antiepileptic drugs has not yet been determined, and their introduction has not replaced that of conventional therapies.

\section{MICROCEPHALY AND EPILEPSY}

The prevalence of epilepsy and learning disability among various types of microcephaly was determined in a study of 66 cases (age range from 2 to 19 years) at the National Research Centre, Cairo, Egypt, and the Department of Human Genetics and Teratology, National Center for Epidemiology, Budapest, Hungary. Microcephaly was classified according to pathogenesis and etiology as isolated (IMC) or multiple (MMC) and primary (PMC) or secondary (SMC). Using Hungarian growth charts, a maximal occipitofrontal head circumference of 2 or more standard deviations below the mean of age and sex-matched participants was accepted as the definition of MC. Cases of craniosynostosis and Down syndrome were excluded. The overall prevalence of epilepsy (mainly generalized tonicclonic) was $41 \%$. It was significantly higher among males. SMC showed a higher incidence of epilepsy and lower IQ when compared with PMC. Learning disability (LD) occurred in $94 \%$, severe in $44 \%$. Severity of epilepsy was correlated inversely with IQ and directly with degree of LD. Participants with MMC due to teratogens (fetal alcohol syndrome) showed a low growth rate. (Abdel-Salem GMH, Halasz AA, Czeizel AE. Association of epilepsy with different groups of microcephaly. Dev Med Child Neurol Nov 2000;42:760-767). (Respond: Dr Ghada MH Abdel-Salam, Department of Human Genetics, National Research Centre, Tahrir, Dokki, Cairo, Egypt).

COMMENT. Primary microcephaly, resulting from anomalous development in the first 7 months of gestation, may be genetic (autosomal recessive), a chromosomal disorder, or caused by various environmental factors (irradiation, in utero infection, chemical). Secondary microcephaly, due to an insult incurred in the last 2 months of gestation or perinatally, may be infectious, traumatic, metabolic, or anoxic in origin (Menkes JH. Textbook of Child Neurology). Almost all will be mentally retarded or have learning disabilities, and $40 \%$ will suffer from epilepsy.

The pathological findings in primary microcephaly, as described in Greenfield JG (Neuropathology) include a small brain, weighing 500 to $600 \mathrm{~g}$ at birth, a disproportionately large cerebellum, basal ganglia, and corpus callosum, simple cerebral convolutional pattern with broad gyri, and typical columnar grouping of nerve cells, histologically. Myelination of the central white matter and long fiber tracts is normal: 